\title{
Meliaceae endémicas del Perú
}

Blanca León ${ }^{1,2}$

${ }^{1}$ Museo de Historia Natural, Av. Arenales 1256, Aptdo. 14-0434, Lima 14, Perú

2 Plant Resources Center, University of Texas at Austin, Austin TX 78712 EE.UU.

blanca.leon@mail.utexas.edu

\section{Resumen}

La familia Meliaceae es reconocida en el Perú por presentar diez géneros y 75 especies (Brako \& Zarucchi, 1993; Ulloa Ulloa et al., 2004), todos ellas árboles. En este trabajo reconocemos tres especies endémicas, en igual número de géneros. Las especies endémicas se encuentran en las regiones Bosques Húmedos Amazónicos, Mesoandina y Bosques Secos, entre los 100 y 1700 m de altitud. Ninguna especie endémica está representada en el Sistema Nacional de Áreas Naturales Protegidas por el Estado.

Palabras claves: Meliaceae, Perú, endemismo, plantas endémicas.

\section{Abstract}

The Meliaceae are represented in Peru by ten genera and 75 species (Brako \& Zarucchi, 1993; Ulloa Ulloa et al., 2004), all trees. Here we recognize three endemic species in the same number of genera. These endemic species are found in areas of Humid Lowland Amazonian Forests, Mesoandean and Dry Forests regions, between 100 and $1700 \mathrm{~m}$ elevation. No endemic Meliaceae have been registered today within Peru's protected areas system.

Keywords: Meliaceae, Peru, endemism, endemic plants.

\section{Cedrela weberbaueri Harms}

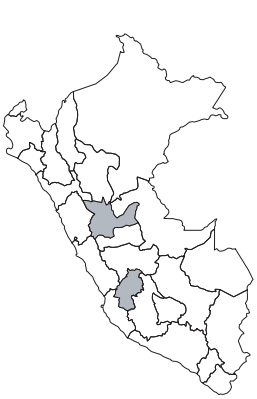

\section{EN, B1ab(iii)}

Publicación: Publ. Field Columbian Mus., Bot. Ser. 8(2): 82. 1930.

Colección tipo: J.F. Macbride 3800

Herbarios: F.

Nombre común: Chulumayo.

Registro departamental: HU, HV.

Regiones Ecológicas: MA, BS; $1700 \mathrm{~m}$. SINANPE: Sin registro.

Herbarios peruanos: MOL (1).

Observaciones: Árbol conocido de dos localidades naturalmente fragmentadas ubicadas en ambientes interandinos, semixéricos. Estos ambientes interandinos de Huánuco y Huancavelica requieren de mayor exploración. La especie fue incluida por Pennington (1981) entre los taxones imperfectamente conocidos, al no poder establecer afinidades con otras. No fue señalada como endémica en Brako \& Zarucchi (1993); sin embargo, aquí se la acepta.

\section{Guarea casimiriana Harms}

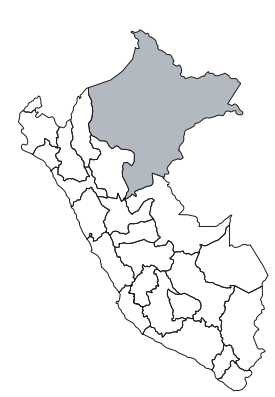

\section{CR, B1a}

Publicación: Pflanzenr. ed. 2, 19bI: 133, 177. 1940.

Colección tipo: E.F. Poeppig 2261

Herbarios: F, NY, OXF, W.

Nombre común: Desconocido.

Registro departamental: LO.

Regiones Ecológicas: BHA; altitud desconocida.

SINANPE: Sin registro.

Herbarios peruanos: Ninguno.

Observaciones: Esta especie se conoce solamente de una localidad cerca de Yurimaguas, en la cuenca del bajo Huallaga. Aparentemente no ha vuelto a ser recolectada desde el siglo XIX.
3. Trichilia ulei C. DC.

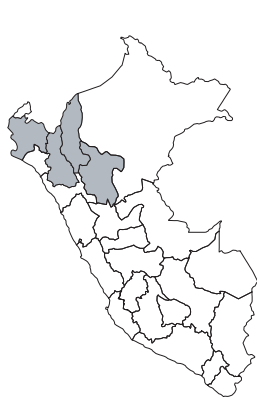

\section{EN, B1a}

Publicación: Annuaire Conserv. Jard. Bot. Geneve 10: 164. 1907.

Colección tipo: E.H.G. Ule 6612

Herbarios: MG.

Nombre común: Desconocido.

Registro departamental: AM, CA, PI, SM. Regiones Ecológicas: BHA; altitud desconocida.

SINANPE: Sin registro.

Herbarios peruanos: Ninguno.

Observaciones: Árbol descrito de una planta recolectada en la cuenca del Mayo, en 1902. Bridgewater et al. (2003) incluyen este taxón en la flora de los bosques estacionalmente secos. Esta especie se conoce de por lo menos cinco localidades. No ha sido registrada en Loreto, si bien ese departamento es incluido erroneamente por Brako \& Zarucchi (1993). 